\title{
Hematological parameters in largemouth bass (Micropterus salmoides) with formalin-preservation: comparison between wild tournament-caught and captive-raised fish
}

\author{
Michelle C Whitehead ${ }^{\text {Corresp., }}{ }^{1}$, Chelsey L Vanetten ${ }^{1}$, Yaxin Zheng ${ }^{2}$, Gregory A Lewbart ${ }^{1}$ \\ 1 Department of Clinical Sciences, North Carolina State University, Raleigh, North Carolina, United States \\ 2 Department of Statistics, North Carolina State University, Raleigh, North Carolina, United States \\ Corresponding Author: Michelle C Whitehead \\ Email address: mcwhite7@ncsu.edu
}

Background. Largemouth bass (Micropterus salmoides) are an economically important freshwater fish species that have been investigated for both the short and long-term effects of stress, secondary to angling. Limited data has been published on the hematological parameters of this species and blood sample stability is a notable limitation of hematologic field studies. A relatively novel technique using $10 \%$ neutral buffered formalin preserves heparinized whole blood and maintains blood cell stability beyond one month in striped bass. The objective of this study was to evaluate the differences in hematological parameters between tournament-caught and captive-raised largemouth bass using whole blood preservation with neutral buffered formalin.

Methods. Two populations of largemouth bass ( $n=26$ wild; $n=29$ captive) underwent coccygeal venipuncture to collect heparinized whole blood for packed cell volume, total solids, and manual differential. Formalin preservation of heparinized whole blood facilitated manual hemocytometer analysis. Results were compared between the populations (tournament-caught, and captive-raised) with Wilcoxon Rank Sums test, a Hotelling's $T^{2}$ test, and Bonferroni simultaneous $95 \%$ confidence intervals to determine significance.

Results. The mean packed cell volume $(44.9 \pm 5.4 \%)$ and total solids $(7.2 \pm 1.1 \mathrm{~g} / \mathrm{dL})$ were significantly higher, while the total leukocyte count $\left(7.08 \pm 1.86 \times 10^{3} / \mu \mathrm{L}\right)$ was significantly lower in the wild tournament-caught population of largemouth bass, as compared to the captive-raised counterparts (PCV $34.4 \pm 7.2 \%$; TS $5.2 \pm 1.0 \mathrm{~g} / \mathrm{dL}$; WBC $\left.16.43 \pm 8.37 \times 10^{3} / \mu \mathrm{L}\right)$. The wild population demonstrated a significantly distinct leukogram characterized by a neutropenia $(24.1 \pm 12.7 \%)$, lymphocytosis $(67.7 \pm$ $13.0 \%)$, and monocytopenia $(8.3 \pm 2.9 \%$ ), while the erythrocyte and thrombocyte counts were not significantly different between populations.

Discussion. Numerous factors have been demonstrated to influence hematologic parameters in fish including age, size, sex, temperature, environmental oxygen level, population density, and infection. The wild population endured stress during angling capture, live-well hypoxia, transport, and extended air exposures at weigh in, which may have caused a stress leukopenia as well as osmoregulatory dysfunction and subsequent hemoconcentration. Further evaluation of seasonal impact as well as increased sample size is warranted to enhance our understanding of largemouth bass hematology.

Conclusion. This study concluded that wild largemouth bass captured via tournament angling have higher packed cell volume and total solids, and lower total leukocyte counts, compared to captive-reared individuals. Through the completion of this study, we demonstrated the successful use of neutral buffered formalin to preserve heparinized whole blood for precise hemocytometer cell counts in a new 
teleost species, the largemouth bass. 
1 Hematological parameters in largemouth bass (Micropterus salmoides) with formalin-

2 preservation: comparison between wild tournament-caught and captive-raised fish

3 Michelle C. Whitehead, DVM, ${ }^{1}$ Chelsey L. Vanetten, LVT, $^{1}$ Yaxin Zheng, ${ }^{2}$ Gregory A.

4 Lewbart, MS, VMD, DACZM, DECZM(ZHM) ${ }^{1}$

5

$6 \quad{ }^{1}$ Department of Clinical Sciences, North Carolina State University College of Veterinary

7 Medicine, Raleigh, NC, USA

$8{ }^{2}$ Department of Statistics, North Carolina State University, Raleigh, NC, USA

9

10 Corresponding author:

11 Michelle C. Whitehead

12 College of Veterinary Medicine, Department of Clinical Sciences, North Carolina State

13 University, 1060 William Moore Drive, Raleigh, NC 27607, USA

14 Email address: mowhite7@ncsu.edu

15

16

17

18

19

20

21

22 


\section{Abstract:}

29 Background. Largemouth bass (Micropterus salmoides) are an economically important

30 freshwater fish species that have been investigated for both the short and long-term effects of

31 stress, secondary to angling. Limited data has been published on the hematological parameters of

32 this species and blood sample stability is a notable limitation of hematologic field studies. A

33 relatively novel technique using $10 \%$ neutral buffered formalin preserves heparinized whole

34 blood and maintains blood cell stability beyond one month in striped bass. The objective of this

35 study was to evaluate the differences in hematological parameters between tournament-caught

36 and captive-raised largemouth bass using whole blood preservation with neutral buffered

37 formalin.

38 Methods. Two populations of largemouth bass $(n=26$ wild; $n=29$ captive $)$ underwent

39 coccygeal venipuncture to collect heparinized whole blood for packed cell volume, total solids,

40 and manual differential. Formalin preservation of heparinized whole blood facilitated manual

41 hemocytometer analysis. Results were compared between the populations (tournament-caught,

42 and captive-raised) with Wilcoxon Rank Sums test, a Hotelling's $T^{2}$ test, and Bonferroni

43 simultaneous $95 \%$ confidence intervals to determine significance.

44 Results. The mean packed cell volume $(44.9 \pm 5.4 \%)$ and total solids $(7.2 \pm 1.1 \mathrm{~g} / \mathrm{dL})$ were

45 significantly higher, while the total leukocyte count $\left(7.08 \pm 1.86 \times 10^{3} / \mu \mathrm{L}\right)$ was significantly

46 lower in the wild tournament-caught population of largemouth bass, as compared to the captive- 
47 raised counterparts (PCV $34.4 \pm 7.2 \%$; TS $5.2 \pm 1.0 \mathrm{~g} / \mathrm{dL}$; WBC $16.43 \pm 8.37 \times 10^{3} / \mu \mathrm{L}$ ). The

48 wild population demonstrated a significantly distinct leukogram characterized by a neutropenia

$49(24.1 \pm 12.7 \%)$, lymphocytosis $(67.7 \pm 13.0 \%)$, and monocytopenia $(8.3 \pm 2.9 \%)$, while the

50 erythrocyte and thrombocyte counts were not significantly different between populations.

51 Discussion. Numerous factors have been demonstrated to influence hematologic parameters in

52 fish including age, size, sex, temperature, environmental oxygen level, population density, and

53 infection. The wild population endured stress during angling capture, live-well hypoxia,

54 transport, and extended air exposures at weigh in, which may have caused a stress leukopenia as

55 well as osmoregulatory dysfunction and subsequent hemoconcentration. Further evaluation of

56 seasonal impact as well as increased sample size is warranted to enhance our understanding of

57 largemouth bass hematology.

58 Conclusion. This study concluded that wild largemouth bass captured via tournament angling

59 have higher packed cell volume and total solids, and lower total leukocyte counts, than captive-

60 reared individuals. Through the completion of this study, we demonstrated the successful use of

61 neutral buffered formalin to preserve heparinized whole blood for precise hemocytometer cell

62 counts in a new teleost species, the largemouth bass.

63

64 Introduction

65 Largemouth bass (Micropterus salmoides) are an economically important freshwater fish species

66 both for recreational and competitive (tournament) angling. This has given rise to scientific

67 investigations into the impact of angling on a variety of factors affecting the fitness of

68 largemouth bass (LMB), both short and long-term. Studies simulating tournament capture have

69 elicited stress responses, which are related to the degree of exhaustion and water temperature, 
70 while often compounded by the length of air exposure, live-well disturbances, and tournament

71 weigh-ins among other factors (Cooke et al., 2002). Short-term consequences are associated with

72 risk of immediate death, as well as a negative energetic balance, which adversely impacts

73 reproductive success due to a reduction in locomotory activity and subsequent diminished nest-

74 guarding behavior (Cooke et al., 2000). The population level effects of catch-and-release angling

75 of black bass (Micropterus spp.) have been summarized for nesting fish, tournament-associated

76 mortality, tournament-related fish displacement, as well as barotrauma, livewell, and weigh-in

77 procedural management (Siepker et al., 2007). Siepker and colleagues (2007) discuss the

78 differences between brief catch-and-release events during recreational angling and competitive

79 angling where a fish commonly endures extended stress including capture, air exposure,

80 placement in livewell for variable length of time, transport to distant location for weigh-in

81 measurements, and then transport for release. Based on previous studies, this can prolong the

82 stressful encounter up to 8 hours in some instances, while introducing additional air exposure,

83 potential overcrowding and hypoxia in the livewell, as well as displacement at the time and

84 location of release (Cooke et al., 2002).

85

86 Extrinsic stress (e.g. population density, handling, transport, etc.) can have an acute impact on

87 the body based on physiologic response to the stressor inducing the release of catecholamines

88 followed by corticosteroids (Clauss, Dove \& Arnold, 2008). If the stressor remains, it is likely to

89 lead to a chronic effect that subsides as acclimation occurs (Clauss, Dove \& Arnold, 2008).

90 Many variables impact fish hematologic parameters, such as species, age, size, diet, season, and

91 oxygen levels (McCarthy, Stevenson \& Roberts, 1975; Clark, Whitmore \& McMahon, 1979;

92 Hrubec, Smith \& Robertson, 2001; Subhadra et al., 2006; Clauss, Dove \& Arnold, 2008; Gaulke 
93 et al., 2014). Selected normal LMB hematologic parameters have been reported identifying a

94 positive correlation of hematocrit and hemoglobin with fish length and age, while mean

95 corpuscular hemoglobin concentration was negatively correlated with age (Clark, Whitmore \&

96 McMahon, 1979). This report however, did not encompass leukocyte or thrombocyte counts

97 (Clark, Whitmore \& McMahon, 1979). Seasonality has been documented to impact hematocrit

98 and hemoglobin levels of striped bass (Morone saxatilis) from the same reservoir, whereby those

99 sampled in the spring had significantly higher values compared to those sampled in the summer

100 (Tisa, Strange \& Peterson, 1983). Water quality may have a direct impact as well, which is

101 evidenced by LMB maintained in a lower oxygen environment for nearly 2 months, leading to

102 acclimation by means of significantly increasing the hematocrit and hemoglobin concentrations

103 (Gaulke et al., 2014). Atlantic sturgeon (Acipenser oxyrinchus oxyrinchus) captive raised at three

104 different hatcheries were shown to have varied hematologic and biochemical parameters related

105 to environmental conditions and warranted the use of individual reference ranges per population

106 (Matsche et al., 2014).

107

108 Fish hematology poses several challenges associated with the presence of nucleated erythrocytes

109 mandating manual cell counts by experienced analysts, and restricted sample viability due to

110 rapid cellular distortion, deterioration, and/or aggregation (Arnold, Matsche \& Rosemary, 2014).

111 Laboratory access and number of samples compound these challenges, especially in field study

112 conditions. Arnold and colleagues (2014) investigated elongation of cell stability in striped bass

113 (M. saxatilis) using 10\% neutral buffered formalin. The study concluded that preservation of

114 freshly collected heparinized whole blood from striped bass in $10 \%$ formalin could reliably 
115 maintain the cell morphology for manual hemocytometer counts for upwards of 1 month

116 (Arnold, Matsche \& Rosemary, 2014).

117

118 To the authors' knowledge, complete hematologic parameters in LMB have not been described,

119 nor have the impacts of tournament capture on hematologic parameters been compared to a

120 captive population. The objective of this prospective study was to compare hematologic

121 parameters of tournament-captured and captive-raised LMB assessed via manual hemocytometer

122 using formalin preserved heparinized whole blood. We hypothesized that there would be

123 hematologic parameter disparity between the tournament-captured and captive raised LMB, such

124 that the total leukocyte count would be higher in the tournament-captured individuals, while the

125 packed cell volume and total solids would be higher in those captive-raised.

126

127 Materials \& Methods

128 Animals

129 Two different populations of fish were evaluated in this study. Twenty-six wild LMB were

130 obtained during a catch-and-release tournament hosted by Bass Pro Shops at Falls Lake State

131 Recreation Area, North Carolina on October 21, 2017. Blood samples were obtained from this

132 wild population in a competitive public setting; just one sample coagulated and was excluded

133 from analysis. Foster Lake and Pond Management, Inc., Garner, NC, USA provided 35 captive

134 reared LMB for the study. Not all blood parameters were included for each animal due to

135 insufficient sample, sample coagulation, or sample processing errors. These fish were sourced

136 from an inspected facility that has not had OIE reportable pathogens detected via regulatory or

137 clinical sample testing (Farm Cat, Inc., Lonoke, Arkansas). The Foster Lake and Pond 
138 Management, Inc. facility was composed of numerous 1,000-gallon (3780 L) tanks each

139 containing 800 gallons (3024 L) of water and approximately 500 fish. A multifaceted filtration

140 system including a bubble bead filter and ultraviolet light was utilized in addition to three back-

141 flushes per week with a commercial sand filter. The water temperature was maintained at

142 approximately 17 degrees Celsius, LED lighting was provided 8 hours per day, and the diet

143 consisted of maintenance Purina Aquamax 600. This second population of fish were captured

144 and sampled in a controlled setting on April 7, 2018, with minimization of potential stressors.

145 The study protocol was approved by the Institutional Animal Care and Use Committee at North

146 Carolina State University College of Veterinary Medicine (Protocol \#18-009-O).

148 Sample collection

149 Based on outward observation, body condition, and gross gill appearance, the fish included in the

150 study were robust without any external lesions. Venipuncture was performed via manual restraint

151 from the lateral approach to the caudal vein. Heparinized sterile 3-mL luer-lock syringes with 22

152 to 25 -gauge needles were used, depending on the fish size, to collect approximately $0.5-1.0 \mathrm{~mL}$

153 blood. Blood smears and hematocrit tubes were immediately prepared in duplicate.

154

155 Sample processing

156 The hematocrit tubes were centrifuged at 13,300 RPM for 2 minutes, followed by measurement

157 of packed cell volume and total solids via refractometer within 8 hours of collection. The slides

158 were fixed and stained with Wright-Giemsa stain within 48 hours of slide preparation using the

159 NC State College of Veterinary Medicine (NCSU-CVM) Clinical Pathology laboratory. The

160 heparinized whole blood was mixed via manual tube inversion and remained at ambient 
161 temperature (approximately 22 degrees Celsius) until all samples had been collected. Within 1

162 hour of sample collection, preservation with formalin was completed in duplicate at each

163 collection site, as defined by Arnold and colleagues (2014), whereby $100 \mu \mathrm{L}$ aliquot of well-

164 mixed heparinized whole blood was placed into $400 \mu \mathrm{L}$ of $10 \%$ neutral buffered formalin for a

165 1:5 dilution and thoroughly mixed via multiple manual tube inversions. The samples were

166 transported at approximately 22 degrees Celsius within 4 hours of collection and stored at 4

167 degrees Celsius for later sample analysis. Dilution of the blood with Natt-Herrick diluent was

168 adjusted to account for the neutral buffered formalin, such that the final dilution of 1:100 was

169 prepared, per previous publication (Arnold, Matsche \& Rosemary, 2014). The standard formulas

170 for the Neubauer hemocytometer (Brightline, Hausser Scientific, Horsham, PA, USA) were used

171 as previously documented (Arnold, Matsche \& Rosemary, 2014). In accordance to Jill E. Arnold

172 (pers. comm., GAL, October 2017), the stability of the cells in neutral buffered formalin is

173 minimally time sensitive, exceeding the reported 1 month interval (Arnold, Matsche \&

174 Rosemary, 2014). As such, the manual hemocytometer analysis was performed within 3.5

175 months of sample collection. Additionally, previous investigation of fresh versus formalin

176 preserved blood in striped bass yielded comparable data, and as such, fresh hemocytometer

177 values were not evaluated in the LMB populations of this study (Arnold, Matsche \& Rosemary,

178 2014). The manual differential leukocyte counts were obtained via an average of 10 fields at $40 \mathrm{X}$

179 objective multiplied by 1,500, while the manual thrombocyte counts were obtained via an

180 average of 10 fields at 100X objective multiplied by 1,000 as reported (Ballard \& Cheek, 2016).

181 Microphotographs of representative cells were captured for inclusion in this publication (Fig. 1).

182 The hemocytometer analyses and manual differentials were performed by an experienced

183 licensed veterinary technician (CLV). 
185 Statistical analysis

186 The means \pm SD for weight, length, packed cell volume, total solids, as well as counts for total

187 leukocytes, neutrophils, lymphocytes, monocytes, erythrocytes, and thrombocytes were

188 calculated. Wilcoxon Rank Sums test was used for comparison between the wild and captive

189 LMB morphometric parameters (weight and length), and cell morphology (neutrophils,

190 lymphocytes, monocytes, and thrombocytes). Significance was set at $P \leq 0.05$ and a Bonferroni

191 correction accounted for multiple comparisons in the data. The analysis was performed in JMP

192 Pro 14 (SAS Institute, Cary, NC). Hotelling's $T^{2}$ test was performed to compare the differences

193 in the remaining blood value measurements (total leukocytes, erythrocytes, packed cell volume,

194 and total solids) between the wild and the captive LMB samples. We then evaluated the

195 Bonferroni simultaneous $95 \%$ confidence intervals to identify which specific variables were the

196 most significant. The analysis was performed in SAS 9.4 (SAS Institute, Cary, NC).

197 Assumptions of independence among the blood samples, equal covariance, and normal

198 distributions were made. Data were visually inspected, t-test are robust against violations of

199 normality. No severe skewness or outliers were observed.

200

201 Results

202 The morphometric parameters of weight and length measured for the wild and captive

203 populations of LMB were statistically different (Table 1). The Hotelling's $T^{2}$ test was conducted

204 on four variables, including packed cell volume, total solids, erythrocyte count, and leukocyte

205 count, demonstrating a significant difference between these two groups (Table 2). Significant

206 differences were detected in the packed cell volume, total solids, as well as counts of total 
207 leukocytes, neutrophils, lymphocytes, and monocytes (Table 3). Total leukocyte count was

208 significantly higher in the captive reared population, while packed cell volume and total solids

209 were significantly higher in the wild population, based on the Bonferroni simultaneous

210 confidence intervals evading zero (Table 4). There was no significant difference between the

211 erythrocyte and thrombocyte values in wild and captive populations. Microphotograph images

212 identify LMB neutrophils, lymphocytes, monocytes, and thrombocytes (Fig. 1).

213

\section{Discussion}

215 The current study demonstrates the successful implementation of formalin preserved heparinized

216 whole blood to conduct hemocytometer analysis on LMB and compares the hematological

217 parameters between a wild tournament-caught population and captive-raised counterparts. We

218 hypothesized that the wild population captured in the angling tournament would demonstrate a

219 detectable stress leukogram induced secondary to the stress of capture and subsequent events

220 such as live-well hypoxia, transport, and extended air exposure during weigh in. Additionally,

221 we predicted a higher packed cell volume and total solids to be demonstrated in the captive-

222 raised population. However, contrary to our predictions, the wild population demonstrated higher

223 packed cell volumes, higher total solids, and lower leukocyte counts, leading to the rejection of

224 our hypothesis. Manual differential revealed significantly higher counts of neutrophils and

225 monocytes as well as lower lymphocyte counts in the captive reared individuals.

226

227 During spawning season, wild adult striped bass at a fork length between 37 to $70 \mathrm{~cm}$ have been

228 documented to have a packed cell volume of $47.9 \pm 10.25 \%$ (Westin, 1978). These striped bass

229 values are most comparable to the LMB wild population in our study (PCV $44.9 \pm 5.35 \%$ ), but 
2301.39 times higher than those in our captive population of LMB (PCV $34.4 \pm 7.16 \%$ ). Hybrid

231 striped bass at 19 months of age and at market size (mean length $26.2 \mathrm{~cm}$, mean weight 0.166

$232 \mathrm{~kg}$ ) had packed cell volumes of $29-36 \%$, which yields a mean nearest our LMB captive

233 population, yet is much lower than our wild LMB counterparts (Hrubec, Smith \& Robertson,

234 2001). The reported leukocyte count of market sized hybrid striped bass ranges from 12.1 - 13.0

$235 \times 10^{3} / \mu \mathrm{L}$, which is lower than the captive $\left(16.43 \times 10^{3} / \mu \mathrm{L}\right)$ and higher than the wild $(7.08 \times$

$23610^{3} / \mu \mathrm{L}$ ) populations of LMB in our study (Hrubec, Smith \& Robertson, 2001). These differences

237 may be related to age and size of the fish sampled, with both of the populations in the current

238 study being larger and heavier than the reported hybrid striped bass (Hrubec, Smith \& Robertson,

239 2001). For example, hematologic changes have been associated with age in growing juvenile

240 hybrid striped bass and juvenile and adult rainbow trout (McCarthy, Stevenson \& Roberts, 1975;

241 Hrubec, Smith \& Robertson, 2001). The increases in packed cell volume and total solids, and

242 concurrent decrease in leukocyte count described with maturity, may be consistent with the

243 expected and observed development of hematopoietic tissues, such as the spleen and head kidney

244 (McCarthy, Stevenson \& Roberts, 1975; O'Neill, 1989; Hrubec, Smith \& Robertson, 2001). In

245 the present study, the wild tournament caught fish were of significantly greater mean length

$246(43.2 \pm 4.6 \mathrm{~cm})$ and mean weight $(0.90 \pm 0.56 \mathrm{~kg})$ compared to the captive individuals (length:

$24729.5 \pm 2.8 \mathrm{~cm}$; weight: $0.42 \pm 0.21 \mathrm{~kg}$ ), which suggests an increased level of maturity for the

248 wild population, subsequently yielding higher packed cell volumes and total solids, with lower

249 leukocyte counts. These age-related changes in hematologic parameters are consistent with that

250 reported in Eastern Atlantic loggerhead sea turtles, whereby increasing hematocrit and plasma

251 proteins, as well as decreasing leukocyte count is seen with age (Casal et al., 2009).

252 Additionally, stress response with release of endogenous catecholamines and corticosteroids has 
253 been reported to manifest as a leukopenia with lymphopenia and relative granulocytosis in fish

254 (Clauss, Dove \& Arnold, 2008). Thus, the leukopenia relative to the captive individuals could

255 correspond to the advanced handling in the LMB population with tournament capture, transport,

256 and weigh-in; although, an overall lymphopenia and relative granulocytosis was not apparent in

257 this study.

258

259 Numerous environmental factors can impact hematologic parameters, such as water quality,

260 temperature, presence of an underlying infection, and population stocking density. The water

261 quality parameters of the lake and tank sources were not within the scope of this study. However,

262 it is known that dissolved oxygen levels can impact hematologic parameters. Largemouth bass

263 acclimate to low levels of dissolved oxygen by enhancement of hemoglobin and hematocrit

264 levels compared to those held at higher dissolved oxygen levels for 50 days (Gaulke et al.,

265 2014). The captive population in our study was receiving oxygen supplementation and this may

266 have dampened the drive to enhance hematocrit in the system. It is important to note that

267 although there was discrepancy between the wild and captive LMB measured hematocrit, the

268 total erythrocyte counts were not significantly different. This suggests an osmoregulatory stress

269 response in the wild LMB population leading to a degree of hemoconcentration, artificially

270 raising the hematocrit. Hematocrit increased in yearling coho salmon in fresh water due to stress,

271 and the investigators concluded that stress induces a bidirectional flux of ions and water across

272 the gill epithelium dependent on the external salinity (Redding \& Schreck, 1983). Alteration in

273 gill epithelial permeability is evidenced by a five-fold increase in the efflux of sodium and

274 chloride in goldfish secondary to handling stress (Eddy \& Bath, 1979). Thus, one could speculate

275 that the elevated hematocrit in the wild population of LMB could be secondary to 
276 osmoregulatory dysfunction; however, measurement of osmolality was not a component of this

277 study objective. The thermal tolerance of LMB was quantified whereby an 8 degree Celsius heat

278 shock produced no differences in the three measured physiological indices of stress between two

279 groups of fish from different thermal environments (Mulhollem, Suski \& Wahl, 2015). However,

280 other differences in these two populations were not elucidated, such as potential behavioral

281 modifications to avoid suboptimal temperature zones, and earlier spawning to ensure optimal

282 developmental temperature for the young (Mulhollem, Suski \& Wahl, 2015). In goldfish, water

283 temperature impacts various hematologic parameters, such that warm-adapted fish had higher

284 circulating levels of hemoglobin, hematocrit, neutrophil counts, and eosinophil counts (Houston

285 and Cyr, 1974; Dunn, Murad \& Houston, 1989). Previous studies have noted higher hematocrit

286 and hemoglobin concentrations in male goldfish and that experimental infection with Aeromonas

287 hydrophila yielded reductions in red blood cell count, hemoglobin and hematocrit in addition to

288 a shift from lymphocyte to polymorphonuclear cell predominance (Brenden \& Huizinga, 1986).

289 Additionally, goldfish maintained in high stocking densities for at least 6 months demonstrated

290 reflexive leukocytosis and lymphocytosis with corresponding reductions in hematocrit,

291 hemoglobin, and thrombocyte count (Burton \& Murray, 1979; Murray \& Burton, 1979). The

292 captive LMB were reared in a tank with known higher stocking density compared to the wild

293 counterparts. Fish raised in close proximity are established to have increased risk of pathogen

294 amplification and transmission of disease, which is contrary to the wide dispersal of wild

295 populations (Moffitt, Haukenes \&Williams, 2004). Although the thrombocyte count was not

296 significantly different between the two populations, the captive-reared individuals did reflect a

297 significant leukocytosis, lymphocytosis, and lower packed cell volume comparative to the wild

298 LMB. Thus, pathogen exposure and stressors secondary to the captive conditions of close 
299 proximity could contribute to the observed lymphocytic leukocytosis, and reduced packed cell

300 volume in the current captive study population.

301

302 The precision of fish hematologic cell counts diminishes rapidly due to cell distortion and lysis

303 (Arnold, Matsche \& Rosemary, 2014). Manual cell counts are necessitated by the morphology of

304 fish cells, which is time and experience-intensive, and is not feasible in large-scale field studies

305 given the number of samples collected. However, the method of formalin fixation previously

306 developed has been proven effective in the hemolymph of lobster (Basti et al., 2010), and the

307 heparinized whole blood of select elasmobranchs, and striped bass (Arnold, Matsche \&

308 Rosemary, 2014). The current study demonstrates the successful use of $10 \%$ neutral buffered

309 formalin in another teleost species, the largemouth bass. Additionally, sample stability was

310 maintained for up to 3.5 months in this study, with no evidence of adverse effects. The extension

311 of cellular morphologic stability provides potential for samples to be transported to diagnostic

312 laboratories for evaluation by trained and experienced analysts for consistency. This technique is

313 revolutionary and will promote the acquisition of precise hematologic information in various fish

314 species that may otherwise remain absent in the veterinary literature.

315

316 There are a number of limitations inherent to this study including the presumption that the

317 externally healthy fish were truly disease free, comparison of presumably isolated genetic

318 lineages, the sample population age and sex was undefined, and the weight and length was an

319 unknown variable prior to sample collection. Additionally, the overall small population size was

320 particularly limited by the confines of the single-day angling tournament, even with the new

321 formalin fixation technique for sample preservation. Nevertheless, this prompts a future direction 
322 of study towards more extensive hematologic comparison with use of the formalin fixation

323 technique to enhance sample size, while conserving result precision. Seasonality has been

324 documented to impact hematocrit and hemoglobin levels of striped bass from the same reservoir,

325 whereby those sampled in the spring had significantly higher values compared to those sampled

326 in the summer (Tisa, Strange \& Peterson, 1983). This finding opposes the data presented here,

327 such that the captive-raised fish were sampled in the spring, yet had lower hematocrit values

328 compared to their wild counterparts sampled in the fall. For this reason, it is less likely that

329 season is the underlying reason for the significant differences observed in packed cell volume

330 and total solids. However, seasonal impact on the leukocyte count is unknown and should not be

331 overlooked.

332

333 Conclusions

334 This study concludes that wild LMB captured via tournament angling have higher packed cell

335 volume and total solids, while demonstrating lower total leukocyte counts when compared to

336 captive-reared individuals. To the authors' knowledge, this is the first report demonstrating the

337 use of heparinized whole blood preservation with neutral buffered formalin for hematologic

338 evaluation of LMB via manual hemocytometer. Further investigation into the influence of

339 season, and exploration of an increased population size is considered essential for expanding our

340 understanding of LMB hematology. Implementation of the formalin fixation technique to extend

341 the stability of whole blood samples should be regarded as a critical component of fish

342 hematologic research moving forward.

343

344 Acknowledgements 
345 Numerous NCSU-CVM students, staff, and faculty contributed to the collection of the data

346 presented in this report. The authors also thank Bass Pro Shops and Fishers of Men National

347 Tournament Trail for their support in provision of the tournament-caught fish, Foster Lake and

348 Pond Management, Inc. for their support in provision of the captive-reared fish, and the NCSU-

349 CVM Clinical Pathology laboratory for their assistance in sample processing techniques and

350 expertise. We thank Cory Sims for assistance in microphotograph capture and Jill Arnold for her 351 expertise and input.

352

353

354

355

356

357

358

359

360

361

362

363

364

365

366

367

\section{References}

1. Arnold JE, Matsche MA, Rosemary K. 2014. Preserving whole blood in formalin extends the specimen stability period for manual cell counts for fish. Veterinary clinical pathology. 43(4):613-20.

2. Ballard B, Cheek R, editors. 2016. Exotic animal medicine for the veterinary technician. John Wiley \& Sons.

3. Basti D, Bricknell I, Hoyt K, Chang ES, Halteman W, Bouchard D. 2010. Factors affecting post-capture survivability of lobster Homarus americanus. Dis Aquat Org. 90(2):153-66.

4. Brenden RA, Huizinga HW. 1986. Pathophysiology of experimental Aeromonas hydrophila infection in gold- fish, Carassius auratus (L.). J Fish Dis. 9:163-167.

5. Burton CB, Murray SA. 1979. Effects of density on goldfish blood-I Hematology. Comp Biochem Physiol. 62A:555-558.

6. Casal AB, Camacho M, López-Jurado LF, Juste C, Orós J. 2009. Comparative study of hematologic and plasma biochemical variables in Eastern Atlantic juvenile and adult 
nesting loggerhead sea turtles (Caretta caretta). Veterinary clinical pathology. 38(2):213-

8.

370 7. Clark S, Whitmore Jr DH, McMahon RF. 1979. Considerations of blood parameters of

371 largemouth bass, Micropterus salmoides. Journal of Fish Biology. 14(2):147-58.

372 8. Clauss TM, Dove AD, Arnold JE. 2008. Hematologic disorders of fish. Veterinary clinics 373 of North America: Exotic animal practice. 11(3):445-62.

374 9. Cooke SJ, Philipp DP, Schreer JF, McKinley RS. 2000. Locomotory impairment of

375 nesting male largemouth bass following catch-and-release angling. North American

376 Journal of Fisheries Management. 20(4):968-77.

377 10. Cooke SJ, Schreer JF, Wahl DH, Philipp DP. 2002. Physiological impacts of catch-and-

378 release angling practices on largemouth bass and smallmouth bass. In American Fisheries

379 Society Symposium (pp. 489-512). American Fisheries Society.

380 11. Dunn SE, Murad A, Houston AH. 1989. Leucocytes and leucopoietic capacity in

381 thermally acclimated goldfish, Carassius auratus L. J Fish Biol. 34: 901-911.

382 12. Eddy FB, Bath RN. 1979. Effects of lanthanum on sodium and chloride fluxes in the

383 goldfish Carassius auratus. Journal of comparative physiology. 129(2):145-9.

384 13. Gaulke GL, Dennis CE, Wahl DH, Suski CD. 2014. Acclimation to a low oxygen

385 environment alters the hematology of largemouth bass (Micropterus salmoides). Fish

386 physiology and biochemistry. 40(1):129-40.

387 14. Houston AH, Cyr D. 1974. Thermoacclimatory variation in the haemoglobin systems of 388 goldfish (Carassius auratus) and rainbow trout (Salmo gairdneri). J Exp Biol. 61:455389461. 
390

391

392

393

15. Hrubec TC, Smith SA, Robertson JL. 2001. Age-related changes in hematology and plasma chemistry values of hybrid striped bass (Morone chrysops $\times$ Morone saxatilis). Veterinary Clinical Pathology. 30(1):8-15.

16. Matsche MA, Arnold J, Jenkins E, Townsend H, Rosemary K. 2014. Determination of hematology and plasma chemistry reference intervals for 3 populations of captive Atlantic sturgeon (Acipenser oxyrinchus oxyrinchus). Veterinary clinical pathology. 43(3):387-96.

17. McCarthy DH, Stevenson JP, Roberts MS. 1975. Some blood parameters of the rainbow trout (Salmo gairdneri Richardson) II. The Shasta variety. Journal of Fish Biology. $7(2): 215-9$.

18. Moffitt CM, Haukenes AH, Williams CJ. 2004. Evaluating and understanding fish health risks and their consequences in propagated and free-ranging fish populations. In American Fisheries Society Symposium. 44:529-537.

19. Mulhollem JJ, Suski CD, Wahl DH. 2015. Response of largemouth bass (Micropterus salmoides) from different thermal environments to increased water temperature. Fish physiology and biochemistry. 41(4):833-42.

20. Murray SA, Burton CB. 1979. Effects of density on goldfish blood-II Cell Morphology. Comp Biochem Physiol. 62A:559-562.

21. O'Neill JG. 1989. Ontogeny of the lymphoid organs in an Antarctic teleost, Harpagifer antarcticus (Notothenioidei: Perciformes). Developmental \& Comparative Immunology. $13(1): 25-33$. 
411 22. Redding JM, Schreck CB. 1983. Influence of ambient salinity on osmoregulation and

412 cortisol concentration in yearling coho salmon during stress. Transactions of the

413 American Fisheries Society. 112(6):800-7.

414 23. Siepker MJ, Ostrand KG, Cooke SJ, Philipp DP, Wahl DH. 2007. A review of the effects

415 of catch-and-release angling on black bass, Micropterus spp.: implications for

416 conservation and management of populations. Fisheries Management and Ecology.

417 14(2):91-101.

418 24. Subhadra B, Lochmann R, Rawles S, Chen R. 2006. Effect of dietary lipid source on the

419 growth, tissue composition and hematological parameters of largemouth bass

420 (Micropterus salmoides). Aquaculture. 255(1-4):210-22.

421 25. Tisa MS, Strange RJ, Peterson DC. 1983. Hematology of striped bass in fresh water. The 422 Progressive Fish-Culturist. 45(1):41-4.

423 26. Westin DT. 1978. Serum and blood from adult striped bass, Morone saxatilis. Estuaries. $424 \quad 1(2): 126-8$. 


\section{Table $\mathbf{1}$ (on next page)}

Morphometric parameters of mean weight and length $( \pm S D)$, measured on the day of blood sample collection for the wild and captive populations of largemouth bass (Micropterus salmoides).

Statistical significance set at $P \leq 0.05$ and a Bonferroni correction accounted for multiple comparisons in the data. Those values in the same row with different superscripts are significantly different. 
1

\begin{tabular}{ccccccc}
\hline $\begin{array}{c}\text { Parameter } \\
(\text { unit })\end{array}$ & $\mathrm{n}$ & Mean \pm SD & $($ Min - Max $)$ & $n$ & Mean \pm SD & (Min - Max) \\
\hline \hline $\begin{array}{c}\text { Weight } \\
(\mathrm{kg})\end{array}$ & 26 & $0.90 \pm 0.56^{\mathrm{a}}$ & $(0.2-2.2)$ & 29 & $0.42 \pm 0.21^{\mathrm{b}}$ & $(0.23-1.45)$ \\
$\begin{array}{c}\text { Length } \\
(\mathrm{cm})\end{array}$ & 25 & $43.2 \pm 4.6^{\mathrm{a}}$ & $(37-53)$ & 29 & $29.5 \pm 2.8^{\mathrm{b}}$ & $(24-40)$ \\
\hline
\end{tabular}

2

3 


\section{Table 2 (on next page)}

Summary of Hotelling's $T^{2}$ test results comparing between the wild and captive-raised largemouth bass (Micropterus salmoides) populations.

NOTE: $d$ represents the averages of the difference between the wild and captive population for each hematologic parameter. Packed cell volume (PCV), total solids (TS), red blood cell count (RBC), white blood cell count (WBC). 
1

\begin{tabular}{ccccc}
\hline Hotelling's $\boldsymbol{T}^{\mathbf{2}}$ test & F & df1 (p) & df2 (n-p) & p-value \\
\hline 94.377 & 22.088 & 4 & 44 & $4.71 \mathrm{E}-10$ \\
\hline
\end{tabular}

2

3

4

5

6 


\section{Table 3(on next page)}

Hematologic results from manual differential and hemocytometer analyses of formalin preserved heparinized whole blood for the wild and captive populations of largemouth bass (Micropterus salmoides).

Statistical significance set at $P \leq 0.05$ and a Bonferroni correction accounted for multiple comparisons in the data. Those values in the same row with different superscripts are significantly different. 
1

2

\begin{tabular}{|c|c|c|c|c|c|c|}
\hline \multirow{2}{*}{$\begin{array}{l}\text { Parameter } \\
\text { (units) }\end{array}$} & \multicolumn{3}{|c|}{ Wild } & \multicolumn{3}{|c|}{ Captive } \\
\hline & $\mathrm{n}$ & Mean $\pm \mathrm{SD}$ & $(\operatorname{Min}-\operatorname{Max})$ & $\mathrm{n}$ & Mean $\pm \mathrm{SD}$ & $(\operatorname{Min}-\operatorname{Max})$ \\
\hline $\begin{array}{l}\text { PCV } \\
(\%)\end{array}$ & 26 & $44.9 \pm 5.4^{\mathrm{a}}$ & $(31-53)$ & 28 & $34.4 \pm 7.2^{b}$ & $(10-48)$ \\
\hline $\begin{array}{l}\text { TS } \\
(\mathrm{g} / \mathrm{dL})\end{array}$ & 26 & $7.2 \pm 1.1^{\mathrm{a}}$ & $(5.6-9.6)$ & 28 & $5.2 \pm 1.0^{b}$ & $(3-8.7)$ \\
\hline $\begin{array}{l}\text { RBC } \\
\left(\mathrm{x} 10^{3} / \mu \mathrm{L}\right)\end{array}$ & 25 & $194.5 \pm 37.4$ & $(109-278)$ & 25 & $189.2 \pm 54.6$ & $(74-321)$ \\
\hline $\begin{array}{l}\text { WBC } \\
\left(\mathrm{x} 10^{3} / \mu \mathrm{L}\right)\end{array}$ & 25 & $7.08 \pm 1.86^{\mathrm{a}}$ & $(4-10.11)$ & 25 & $16.43 \pm 8.37^{b}$ & $(5.44-44.56)$ \\
\hline $\begin{array}{l}\text { Neutrophils } \\
(\%)\end{array}$ & 26 & $24.1 \pm 12.7^{\mathrm{a}}$ & $(3-53)$ & 25 & $35.7 \pm 15.8^{b}$ & $(7-80)$ \\
\hline $\begin{array}{l}\text { Lymphocytes } \\
(\%)\end{array}$ & 26 & $67.7 \pm 13.0^{a}$ & $(38-90)$ & 25 & $52.8 \pm 14.8^{b}$ & $(16-80)$ \\
\hline $\begin{array}{l}\text { Monocytes } \\
(\%)\end{array}$ & 26 & $8.3 \pm 2.9^{a}$ & $(1-16)$ & 25 & $12.2 \pm 4.9 \mathrm{~b}$ & $(4-22)$ \\
\hline $\begin{array}{l}\text { Thrombocytes } \\
\left(\mathrm{x} 10^{3} / \mu \mathrm{L}\right)\end{array}$ & 25 & $15.3 \pm 5.8$ & $(4-30)$ & 25 & $18.9 \pm 9.8$ & $(8-53)$ \\
\hline
\end{tabular}

3 


\section{Table 4 (on next page)}

Summary of $95 \%$ Bonferroni simultaneous confidence interval results between the wild and captive largemouth bass (Micropterus salmoides) populations.

NOTE: $d$ represents the averages of the difference between the wild and captive population for each hematologic parameter. Packed cell volume (PCV), total solids (TS), red blood cell count (RBC), white blood cell count (WBC). 
1
2
3

\begin{tabular}{|c|c|c|c|}
\hline \multirow{2}{*}{ Parameter } & \multirow{2}{*}{ d } & \multicolumn{2}{|c|}{ 95\% Confidence Intervals (CI) } \\
\hline & & Lower Bonferroni CI & Upper Bonferroni CI \\
\hline PCV & -10.45 & -14.38 & -4.14 \\
\hline TS & -1.97 & -2.87 & -0.87 \\
\hline RBC & -5.30 & -51.49 & 37.53 \\
\hline WBC & 9.35 & 3.32 & 14.77 \\
\hline
\end{tabular}

4

5

6 


\section{Figure 1}

Microphotograph images demonstrating largemouth bass (Micropterus salmoides) hematologic cell morphology with Wright-Giemsa stain at 500X magnification (50X power).

Neutrophils (solid arrows) showing pale cytoplasm with sparse granulation, and an eccentric bi-lobed or unsegmented nucleus. Monocytes (stars) are identified showing the typical eccentric nucleus, abundant vacuolated and deeply basophilic cytoplasm with occasional blebbing of the plasma membrane. Lymphocytes (dashed arrows) are identified with a heterogenous nucleus, scant amount of deeply basophilic cytoplasm and occasional blebbing of the plasma membrane. Thrombocytes (triangle arrowheads) are identified with an irregularly shaped, deeply homogenous basophilic nucleus, and pale cytoplasm, often with cytoplasmic spindle-like extensions. Note that the thrombocytes in these largemouth bass samples did not demonstrate the typical piriform or spindle-form shape, but had more abundant cytoplasm in comparison to the lymphocytes. (A) Representative images of neutrophils (solid arrows), monocytes (stars), and thrombocytes (triangle arrowheads). (B) Lymphocytes (dashed arrows) distinguished from thrombocytes (triangle arrowheads) by the scant and deeply basophilic cytoplasm. (C) Neutrophils (solid arrows), monocytes (stars), and a single thrombocyte (triangle arrowhead). (D) Neutrophils (solid arrows), lymphocytes (dashed arrows), a monocyte (star), and a single thrombocyte (triangle arrowhead). 


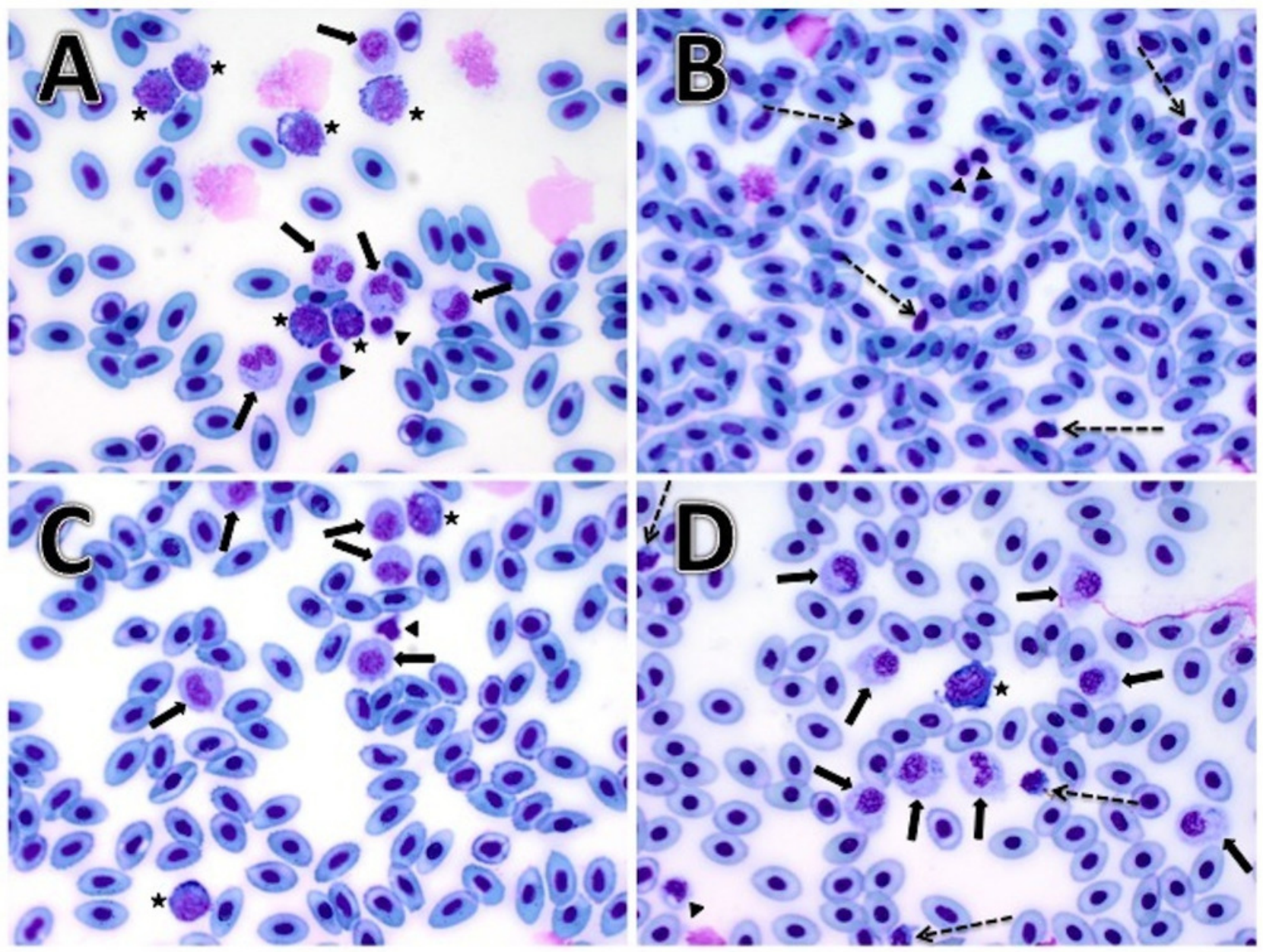

